\title{
ENTREVISTA CON XAVIER RUBERT DE VENTOS
}

R. P. (Revista «Papers»): Eimpezar una entrevista siempre es complicado, sobre todo cuando no hay un protocolo de preguntas o temas cerra. do. Nosotros hemos preparado este guión para que sirva, más o menos, como pauta temática de la conversación. Como puedes ver, el tema central es el de la perspectiva tradición-modernidad-postmodernidad, enfocándola especialmente desde la categoría espacio y su percepción por la colectividad.

X. R. (Xavier Rubert): En un sentido, el espacio es un tipo de relación, de vínculo social, relativamente neutro. Precisamente la reforma de Cístenes en Atenas consistió en suplir las relaciones de linaje por telaciones de tipo puramente espacial; por demos, que se definen por su ubicación. Esta neutralidad del matco espacial posibilita entonces, como vio Simmel, un tipo de telaciones que son democráticas, que son topológicamente neutras, y que, pot lo tanto, no vinculan a la gente de otra manera que no sea por su emplaza. miento. El emplazamiento es la más neutra de las «definiciones» posibles de un individuo. Me asusta mucho más que a alguien lo definan por la sangre, por la raza, por la estixpe, etc. En cambio, la espacial es una definición puramente descriptiva.

R. P. Te estás tefiriendo a la definición de un individuo por su emplazamiento como una definición neurra. Pero la percepción del individuo de su propio emplazamiento, ¿es tan neutra como esto?

X. R. No, no es neutra; innediatamente queda mitificado su entorno. 
Pero en todo caso los santos «territoriales》 cristianios son unos santos, por así decir, más democráticos que los santos o espíritus ligados a los linajes, lares o penates. Yo creo que es un progreso democrático que los santos sean definidos topológicamente, que yo tenga la Mare de Déu de Montserrat en vez de la Mare de Déu de los Rubert. No niego que tiende automáticamente a producirse una mitificación de esta cosa tan poco mítica que es el espacio, pero de una manera u otra presenciamos aquí una evolución paralela a la convencionalmente descrita como paso del animismo al politeísmo y al monoteísmo. Es una evolución que tiende a la neutralización de relaciones que posteriormente quedan remitificadas, pero que van tomando cada vez formas más objetivas.

Por otra parte, es tatubién un hecho que la escala del espacio vivido y experimentado determina muchas cosas. Pierre Clastres atribuye la «guerra de todos contra todos» en las tribus primitivas a la intuición que en ellas se tiene de que a pattir de una cierta dimensión, no sólo en el número de individuos sino del mundo simbólico percibido, nace la división del trabajo entre gobernante y gobernado, trabajador y administrador, burócrata y servidor, etc. La guerra de todos contra todos primitiva sería así un intento de mantener aquella escala espacial dentro de la cual no emerge la jerarquía. Aunque con otra intención, ya Max Weber había afirmado que la universalidad del comercio generaba la universalidad del pensarmiento. También es verdad que genera la abstracción del pensamiento y el razonamiento puramente especulativo. La escolástica, el pensamiento escolástico, pudo llegar a unos niveles de abstracción grandes porque el poder espiritual residía en una Roma lejana, abstracta, a menudo imaginatia. De ahí que el espacio en que se vive tenga también efectos sobre el sistema especulativo. No hay que decir, es un tópico, que lo que separa a S6crates de los estoicos o de los epicúreos es el cosmopolitismo. Lo ha dicho mucha gente y es clarísimo que no se puede seguir pensando como pensaba Sóctates si hay carreteras. S'ba acabat el bròquil. Cuando la Vía Augusta Ilega de Roma a Batcelona no hay Sócrates que crezca; el pensamiento deja de ser «político» para hacerse «cosmopolítico». Esto yo lo vivo realmente así y daría pie a hablar de la situación en la que hoy nos encontramos. A un nivel histórico, a cualquiera que afronte hoy el problema se le plantea un tema, que vosotros tocáis por lo menos en dos puntos del guión, que es el de la privatización del espacio y la situación del espacio simbólico. En mi opinión hay una relactón inversa entre espacio simbólico y espacio real. Hoy en 
día las simbologias son privadas, son simbologías individuales o de subgrupos. De un modo u otro yo tengo que generar un espacio simbólico en la precisa medida que no tengo un espacio real y cierto. En el conocido estudio sobre la isla de James se observó un aumento de la adrenalina absorbida por el páncreas, propotcional a la densidad de animales. A partir de ello se pensó que hay una densidad «psicologica» a partir de la cual los animales pueden aún comer, pero en la que empiezan a segregat adrenalina, es decir, agresividad. Hay una densidad que empieza a set ansiógena. Pues bien, en estos espacios en los que la densidad empieza a ser ansiógena, hay un aumento en la creación de espacios simbólicos, ya que no hay espacio físico suficiente. Si esto es así, se explica bastante que cuanto menor es el espacio, más ritualizada o "simbólica" sea la relación con él. Hay una ritualización del trato del médico con el enfermo que es análoga: como viola el espacio íntimo del individuo, el médico tiene que tener el gesto profesional, técrico-científico. Ha de ser simbólicamente científico además de serlo prácticamente, en el mismo sentido en que se decía que la mujer no sólo ha de ser casta, sino que debe parecerlo. Ahora bien, cuando no se puede generar este espacio simbólico sustitutivo, entonces se agravan sumamente los problemas de jerarquía. En los lugares pequefios, prisiones, colegios, etc., acostumbra a existir una jeratquía feroz entre sus miembros porque la gente no tiene espacio físico e intenta así crearse un espacio simbólico; o sea, la no disponibilidad de espacio propio conduce a la creación de una jerarquía de espacios simbólicos. Por aquí sale una vez más el carácter democrático de la espaciaJidad. Por otra parte (y esto sería una acotación historicista al terna), yo recuerdo cuando leía aquello del animismo, politéismo y monoteísmo como etapas comptianas en el progreso del espíritu. Hay un progreso en el gesto religioso que consiste en absorber el espíritu del bosque, el espíritu del río, etc. (animismo), teunitlos a todos primero en un Olimpo (politeísmo), luego en una persona (monoteísmo), construirle entonces una casa (iglesia) y en vez de estar todo el día teniendo una telación titual con la casa y con todo, limpiar así el mundo de dioses y concentrarlos a todos en un espacio privado. Es un gran y primer gesto de secularización del mundo: es un gesto genial.

Como que soy más bien biologista (aunque esto de ser biologista es muy de derechas y está mal visto), creo que habría que hablar también de cuáles son los proyectos culturales que tienen valor adaptativo y cuáles no lo tienen. Han sobrevivido así las transfor- 
maciones culturales con valor adaptativo, como es el caso de la prohibición del incesto que tiene claramente este vaior. Creo, pues, que la teligión era un invento de un gran valor adaptativo que permitía un trato secular con el $90 \%$ de las cosas de este mundo, una concentración en el espacio y en el tiempo de las relaciones tituales, una división del trabajo y de las funciones muy clara y una separación entre espacio sagrado y profano. Es decir, comenzaba una segmentación del espacio y del tiempo, todo esto de lo que después nos hemos quejado, pero que no hay duda que tiene una eficacia técnica brutal. Encuentro que la religión es la expresión más visible y espectacular de este proceso.

R. P. En tu exposición has tocado un tema que nos preocupa y que es la construcción privada de significados. Estabas apuntando el hecho de que la teligión es un primer proceso de secularización del mundo y, por lo tanto de ordenación, de segmentación del tiempo segín un significante, de todas maneras global, pero nos parecía que en la actualidad esta ordenación significativa global que daba sentido a la segmentación del tiempo y del espacio se ha difuminado. Por lo que parece se va hacia una construcción ptivada de significantes en la que ni siquiera esta segmentación primera que produce la religión tiene sentido. Nos encontramos con una construcción privada de significantes, respecto del espacio y del tiempo en la que, a pesar de su diversidad y de este carácter de privacidad que tiene, se produce una estandarización, y ésta sería la pregunta, que no sabemos si es susceptible de ser leída como una uniformidad de rango supetior, es decir, como un nuevo significante global capaz de ordenar y segmentar.

X. R. Vuestra pregunta es muy pertinente. Este tema está en el fondo de la preocupación de Slater, Sennett, Leach y tantos otros, por lo que ha venido a llamarse el nuevo "narcisismo», el "mundo suburbial», la búsqueda de la identidad en la «intimidad» o aún de la ctisis de un ámbito propiamente social (lo que antes se llamaba la «sociedad civil») a que alude Touraine. A mí este fenómeno me parece asociado o paralelo a la crisis de la actitud «vanguardista». El arte de vanguardia fue el intento de romper códigos y de crear códigos nuevos, subjetivos. Esto durante un tiempo, hasta los sesenta, se vendió como la alternativa a un arte convencional en el que habia que aprender códigos figurativos, representativos, etc. A partir de los setenta se empezó a hablar de otra forma. Se empezó a decir que existía ya un «lenguaje» moderno del arte, un nuevo «código» que vendría, digamos, del cubismo, de Kandinsky 
- Malevitch. Traduciendo vuestra pregunta: ¿Es la genezación de espacios simbólicos privados algo ya tan generalizado que lo podemos definir como un «nuevo» código? Los setenta dijeton sí. Fijaos que es significativo el cambio de retórica justificativa del arte moderno. Hasta los sesenta «porque rompe códigos», en los setenta «porque hay un lenguaje moderno». Los padres fundadores del arte moderno habian intentado romper todos los códigos, pero hoy estaríarnos en condiciones de hacer una lectura estilística del racionalismo arquitectónico (que no se quería estilístico), una lectura retórica del cine de vanguardia (que se quería antirretórico), etc. El estructuralismo fue el más sofisticado intento de explicar cómo aquello que había aparecido como l'éparpillement de códigos priva. dos, en definitiva, tenía un código común y que había una posibi. lidad de lectura perversa, sistemática, de fenómenos que se pre. sentaban como dispersos o asistemáticos. Pero hoy hemos constatado algo más grave: la creatividad que posibilitaba la existencia de un código clásico, y vuelvo a vuestro tema, las posibilidades de invención que se daban a partir del clasicismo arquitectónico (y que posibilitaron un expresionismo feroz como Miguel Ángel o un estructuralismo casi de ingeniero como el de Brunelleschi), todo esto no lo permite el código «moderno» de la arquitectura. Este éparpillement o difuminación sistemática de códigos ha tenido sus límites. No da más de sí. En los años setenta uno podía aún creerse que sería, en arquitectura por ejemplo, racionalista y a la vez simbólico e histórico. En filosofía podíamos creenos también ser «modernos y antiguos» a la vez. Teníamos Marcuses, respondíamos a la tealidad virulenta de los sesenta y al mismo tiempo recuperábamos aquel Kant de La crítica del juicio. Podíamos creernos que jugábamos a todas las cartas.

En los ochenta se nos ba acabat el bròquil. Si nos ba acabat tot el bròquil. Nosotros como filósofos y los arquitectos como atquitectos nos encontramos con el mismo problema. A los arquitectos qué les pasa. Que si antes hacían un poco de Bauhaus tocado de tendenza italiana y de historicismo con un poco de Rossi y de «tecuperación» de no sé qué, se podian creer que estaban generando un estilo que respondía a la realidad. Hoy en día esto ha hecho crisis y qué hacen. Hacen columnas. Columnas y capiteles. $Y$ no hay nadie que se pueda hacer entonces la ilusión de que esto es la respuesta "cien. tífica» a la tealidad misma de los suburbios, del crecimiento utbano y todo lo demás.

Con nosotros los filósofos pasa lo mismo. Si eras partidario de 
Lowental, de la escuela de Frankfurt, tocado de Foucault o Haberraass, etc., podias cteerte que, por un lado, recuperabas la tradición filosófica del idealismo y del marxismo, y, por otro, hablabas de y respondías a la realidad histótica de tu tiempo. Hoy en día, yo, por ejemplo, me siento kantiano. Pero no Kant-Hegel-marxistofreudiano, que es como ser moderno-bauhausiano-tradicional o poulanziano, que recuperaba el formalismo pero en cambio le daba una dimensión marxista que superaba el economicismo, pero, sin embargo, asumía la dimensión simbólica que el marxismo había olvidado, bla, bla, bla. Todos estos cuentos ya no nos los podemos creer. Estamos sin lenguaje, sin «código» moderno. Por qué digo que me gusta esto. Me gusta porque yo creo que nos ayuda a mirar y a pensar, nos obliga a ello. En la medida que pensamos en la realidad, sólo repensamos y vamos más allá de los tópicos en uso cuando nos quedamos sin teorías, códigos o modelos «para todo». Yo pude pasar diez años siendo marzo - no sé qué. Mi hijo no puede Los atquitectos pudieron pasar diez años creyéndose que exan síntesis de racionalismo, modernidad y tradición. Los chicos de hoy no pueden ya hacerse la ilusión de que están hablando un lenguaje que tecupera su tradición cultural y, a la vez, tesponde a los pro biemas actuales. Esta ficción se ha acabado. Hace diez años que tengo esta sensación. Y veo que la empieza a tener más gente. No quiero hacer profetismo o algo parecido, pero me satisface.

R. P. Siempre es gratificante encontrar coincidencias entre personas que trabajan en diferentes campos de conocimiento y que llegan a consideraciones similares. En este caso sería la conciencia de crisis, la conciencia de que lo que hablamos...

X. R. ... y la relación de to que hablamos con las cosas de las que hablamos...

R. P. Exacto, y esta relación hace aguas por todas partes, Como tú dices acertadamente, s'ba acabat el bròquil. Se ha acabado la ficción de que estamos haciendo sociología y de que estamos hablando de las relaciones sociales. Estamos hablando de cosas que no sabemos. Estamos haciendo abstracciones y las tomamos como réplica autén. tica de la realidad. En cualquier caso, hay una posible lectura simétrica o recíproca, llámala como quieras, que están haciendo una serie de personas y que consiste en entender este postmodernismo como un avance hacia la estabilidad creativa. Es decir, que esta especie de collage de tecuperar la tradición sin abandonar lo que había significado el modernismo de ruptura de códigos y demás, es la única condición de posibilidad de entrar en una nueva fase de 
estabilidad creativa, por decirlo de algún modo. Y lo explicaban en términos de autonomía del código. Los modernos, contra su propia intención, elaboraron un código autónomo que les funcionó, pero que es limitado. Por lo tanto, la única posibilidad de ganar estabilidad es la de ampliar el código incorporando los elementos que los modernos habían olvidado, para poder seguir siendo creativos. Nuestra impresión es que esta lectura es bastante opuesta a la que tú estás haciendo.

X. R. Radicalmente. Yo creo que esto es una lectura demasiado moderna (o modernosa) de lo postmoderno. Entiendo muy bien que se hagan lecturas de este tipo, porque profesionalmente es a lo que uno tiende. Pero es un modernismo de profesores.

R. P. No existe entonces ningún rasgo diferencial entre este tipo de lecturas y las lecturas modernas. Es continuar siendo moderno, sólo que un poco más moderno.

X. R. Mira, las capacidades de asimilación son muy grandes. De la misma manera que el sistema social tiene una gran capacidad de asimila. ción de los movimientos sociales, el intelecto tiene una tendencia a la entropía y, por lo tanto, a reducir los procesos nuevos a los procesos que ya ha tratado; a asimilar un fenómeno nuevo al modelo de otro que ya conoce. Una situación nueva a nivel teórico se parece a una situación nueva a nivel vital. A los viudos o a los divorciados, por ejemplo, su nueva situación les comporta unos costos pero también unas ganancias. Son personas que estaban jugando a una cosa y de golpe se ven enfrentados a una realidad diferente: en vez de jugar «a dos» han de jugar de «a uno». Y es entonces cuando muchos de elios tratan de evitar esta experiencia nueva y traumática tratando de recrear una situación que se parezca a la antefior. Y lo mismo ocurre con la teoría a menudo: se trata entonces de hacer "casar» la situación nueva al modelo teórico que ya poseíamos. De lo que se trata, sin embargo, es de reconocer que muy a menudo nuestros modelos no son más que «modelitos», ficciones más o menos cómodas u' operativas, pero ficciones al fin. $\mathrm{Y}$ aquí es donde empalmo con Kant. Kant es el único pensador que tuvo el valor de advertir que en el mundo moderno, cuando ya no somos griegos ni vivimos en ura «polis», cuando ba irrumpido la desmesurada subjetividad cristiana con su correspondencia espacio-simbólica, todas las maneras de entender el mundo son «ficciones». Son tan ficciones que el hombre puede definirse incluso como aquél que genera ficciones.

Pero la lección de Kant inmediatamente se olvidó. Hegel, la feno. 
menología, Marx, Heidegger volvieron a decirnos que si sofisticamos el modelo podemos seguir hablando de las ucosas mismas» Xant señaló una ruptura entre lo sensible y lo inteligible Hegel tuvo la genialidad de reconstruir un sistema coherente a partir de la «ruptura» kantiana. De él salen los marxismos, existencialismos, positivismos y demás modelitos a escala. Kant anuncia que se ha roto la relación entre conocimiento y realidad, que se tiene que tomar el conocimiento como un modelo artificioso de la realidad y que cualquier pretensión de encarnación o tealización es un puro delirio. La tradición idealista da, vuelve a dar, credibilidad a estos delirios, y es a partir de ella que se genera el proceso del que hablo en mi libro De la modernidad, los dioses se van encarnando a niveles cada vez más bajos. Hegel los había hecho bajar hasta el Estado y la Razón. Pues bien: Marx los lleva hasta la infraestructura económica, por debajo del Estado, y Freud hasta el Inconsciente, por debajo de la Razón. Después de Marx y de Freud, más abajo del inconsciente, aparece el deseo preedípico y más abajo que la economía, la disidencia. Para mí la ideología antipsiquiátrica o disidencial de estos años es todavía heredera de un hegelianismo, que quiere y cree en una encarnación de la Razón en la historia; actuando como si existiera un sitio (un tiempo se pensó que era el proletariado, Iuego la juventud, o el deseo, o...), un depositario de la razón histórica con el que basta estar o identificarse para asegurar la conexión entre su pensamiento y la realidad. Yo creo que todos estos procesos de penetración o identificación son hegelianos, y que las teorías a las que hacéis teferencia o el deleuzismo, el disentismo, el neojudaísmo, el neomonoteísmo, el neopoliteísmo el neobiologismo, etc., todos son intentos todavía de teencarneción. Uitimos bastiones de lo que parece que, gracias a Dios, se desmorona definitivamente: del hegelianismo del que yo he vivido y del que mi hijo no podrá vivir. No se lo que hatá mi hijo, pero seguro que no jugatá a lo que yo he jugado y esto a mí me alegza. Quizás es muy teórico todo lo que estamos diciendo, pero es lo que ahora me preocupa.

R. P. Probablemente, pero es exactamente una preocupación que compartimos bastantes y tú tienes la capacidad de sistematizarlo y verbalizatlo. Describes perfectamente una vivencia que tenemos muy presente, por lo menos los que nos dedicamos a la docencia. Es una sensación ineludible la de sorprenderte cada día delante de tus alumnos explicando cosas que íntimamente no puedes creerte. $\mathrm{Y}$ te preguntas qué les estás explicando, qué credibilidad puede 
tener lo que dices. Naturalmente que te montas la coartada de decir aquello de que es mejor que les expliques esto que no otra $\cos a . .$.

X. R. X es verdad, si lo aceptas como coartada. Es lo que dijo Kant. Pero es necesatio saberlo, es necesario saber que se trata de una coartada.

R. P. Puede ser que este sea un discurso muy teórico, pero resulta que al nivel en que se está tratando hoy el problema del espacio y, sobre todo, del espacio teducido, se hace preciso este tipo de discurso más abstracto. Nosotros tepetimos muchas veces lo de que se hace preciso construir teóricamente los objetos de conocinniento. No nos podemos continuar creyendo esta especie de topologías heredadas directamente de la historia natural, el topos clasificado y el topos ordenado, o el discurso sociológico sobre el topos, aquello del espacio como la posibilidad de coexistencia, etc. En nuestra opinión ha de pasarse a un tipo de planteamiento en el que el espacio deje de ser la exterioridad en la que pasan y se sitúan las cosas y empiezan a entender el espacio como coexistencia misma. Coexistimos como espacio y todos estos discursos de la topogénesis y demás, que son sugerentes a nivel de desarrollo parcial de una teoría, han de ceder la palabra a otro tipo de análisis. En particular la topogenética me recuerda los planteamientos de la biogenética, que son muy respetables pero que nunca alcanzarán la construcción teórica de la categoría «Vida».

Del mismo modo, tampoco podremos construir teóricamente la categoría de «espacio» desde la topogenética.

X. R. Me parece exacto. Esto me sugiere el tema de los espacios descualificados. De la misma manera que a nivel simbólico ha habido una pérdida del cordón umbilical que de alguna manera más o menos mediata aseguraba la conexión de nuestro discurso con la cosa, a nivel más social como vosotros decíais, Ia única característica o virtus conectiva de este espacio es su descualificación. Haciendo un discurso banalmente sociológico, podríamos decir que todos los espacios importantes son espacios no cualificados. El problema es cómo se genera un espacio no cualificado. La generación de lo no cualificado da para todo tipo de discurso ideológico y de cualquier otro tipo. Pero lo cierto, y de ello patece que ya empieza a darse cuenta todo el mundo, incluso los arquitectos, es que los espacios de cualidad de cualquier vivienda eran los no cualificados. En mi casa, cuando era pequeño, el espacio mítico era el planchador y el office. Era un lugar en el cual cabían todas 
las relaciones posibles entre espacio servidor y espacio servido, espacio instrumental y espacio final, espacio "consciente" (el comedor) y espacio «inconsciente» (ia cocina), espacio de sirvientes/ espacio de señores. El planchador era el lugar en el que se producian cruces. A veces estaba mi madre, estaban las criadas, a veces los niños... creo que los espacios que tienen una virtus simbólicamente son espacios no cualificados de este tipo. Esto en la ciudad también está clarísimo. Los únicos lugares que tienen «calidad» y permiten telaciones no codificadas son los no cualificados. Este es el drama de los diseñadores actuales queriendo crear un espacio cualificado para el juego, un espacio para la interacción, etc. $Y$ es que tanto a nivel urbano como a nivel doméstico, los espacios de calidad son los espacios que se nos han escapado. Hay un ejemplo magnífico de ello en lo que ocurrió en un hospital de viejos que tenía una escalera y un solárium que no se usaba pata nada. Llegó como directora una señora muy moderna, descubrió que el solárium, como las terracitas de las casas burguesas que no se usan, exa petfectamente inútil, y clausuró la escalera y el solárium. Pero, entonces, se empezó a generar una inquietud tremenda en el asilo. ¿Qué había pasado?: la escalera que subía al solárium, al no utilizarse éste, era utilizada por los viejos más dinámicos, o bohemios, que querian fumar o explicarse cosas a escondidas como espacio de teunión.

Era un espacio no cualificado y funcionaba como lugar de calidad. Desde que este espacio «inútil» fue eliminado, los que se teunían alli fueron teintegrados a la sala de juegos, que había sido tomada por los «seffores», o a la televisión, que había sido tomada por las «señoras», con lo que el tnuevo grupo exiliado de una escalera pronto entró en conflicto. Otro caso de utilización del espacio no cualificado, esta vez con fines terapéuticos, es el del hospital Paul Rivière que se construyó hace unos quince años en el sur de Francia. La experiencia se basaba en la generación de espacios terapéuticos, siguiendo la fisolof́́a de Kurt Lewin y demás, retopologizando la temática psicoanalítica, por un lado a través del biologismo y por otto del neofreudianismo. $Y$ es que ambas corrientes tienden, de una manera u otra, a una retopologización del discurso sobre el inconsciente. (De ahí que se tienda a hablar de los espacios externos que están en correspondencia con los espacios internos.) En el centro de este hospital crearon una especie de comedor-sala de juegos y en la periferia situaron unos pequeños claustros en los que estaban los habitáculos de los locos, muy próximos entre sí, 
con mucha luz y un suelo diferente. Entre la zona de vivienda y Ia del comedor-sala de juegos había una zona no cualificada con el suelo menos trabajado, menos iluminada, más abierta, es decir, un no man's land que tenía que ser atravesado varias veces al día para desplazarse de una zona a la otra. Esta terapéutica se seguía de la hipótesis de que los esquizofrénicos han perdido la conexión entre el «nido» y el «terreno de caza», entre lo privado y lo público. De esta manera estaban obligados, una y otra vez, día a día, a salir de casa, atravesar lo desconocido y entrar en lo público.

En definitiva, este es el gesto de la curación psicológica: salir de casa, desprivatizarse, pasar por la tierra de nadie y recuperar un mundo habitual a otro nivel.

Pero me veo yo mistno tratando ahora de legitimar «objetivamente», con ejemplos «científicos» mis propias opciones o posiciones. ¿No creéis?

R. P. Efectivamente. Lo que sucede es que en general esto todavía se da como vivencia no verbalizada, muy informal, porque es difícil formalizarla, pero que es el fundamento de la angustia generalizada que se vive.

$X . R$. Me vais a permitir que os pregunte yo. ¿Por dónde nos saldremos? Por un lado, se da el intento de tecuperar un discurso mo derno, al cual obviamente estamos acostumbrados y es el que nos sale fácil. Por otro lado, la gente de menos de treinta años no cono$c e$, por suerte o por desgracia, este discurso moderno. Lo veo en mis hijos. Por lo tanto, esta nueva experiencia factual de la desconexión, de que la relación del discurso con la realidad es puramente hipotética, constituye un fenómeno reciente. La gente no tiene estos sistemas de conexión muestros ¿a qué tiende o qué tenderá a hacer? ¿Buscará una coartada, sentirá nostalgia de un mito integrador...?

R. P. Lo de la recuperación de un mito integrador es una de las vías más comúnmente utilizadas. Dicho de otra forma, la búsqueda de un significado ordenador de la vivencia global. Nosotros, los modernos, jugábamos a la esquizofrenia controiada. Nos ordenábamos por separado nuestra vida íntima, nuestra vida pública con sus diferentes significados. Por lo que se ve, esta gente joven está buscando una tecuperación o la creación de un significado que ordene toda su vida como un global, como un todo. Así se explica toda suerte de recuperación de religiones orientales, de mitologías, de id̉eologías cosmológicas, etc... Se observa este tipo de procesos, sobre todo, en la gente inteligente, la gente inquieta, 
la gente angustiada. Hay otros que se dedican a pasar. Esta gente inquieta está, por ejemplo, con el rollo de la simbología en el sentido más esotérico, buscando el símbolo de los símbolos, el árbol de la vida, descubriendo el pitagorismo, etc... En definitiva, buscando este elemento macro, este significante que les ordene toda su existencia.

Por otra parte, hay todavía un contingente de individuos que juegan a este postmodernismo moderno, que ya no son hijos ni de Althusser ni de Poulantzas, pero que están enganchados en una especie de espiral a la baja, los nuevos filósofos franceses, etc., recreando una especie de mito de la disidencia que, sobre todo, conduce al silencio. Un poco es aquello de que como no podemos disentir porque la disidencia casi siempre se convierte en dogma, no hablamos. Como no podemos hablar de las cosas, ni lo que hablamos se aproxima a las cosas, no hablamos. Esto que como salida personal puede ser incluso gratificante, como propuesta colectiva genera preocupación. Referido a esto, el otro día en un curso estábamos planteando la pérdida de la capacidad de movilización que las ideologías tenían en tiempos no muy lejanos. Se ha acabado la comunión con una idea que adexnás te agitaba y te empujaba a hacer cosas, a hacer determinados tipos de análisis, a llevar adelante determinadas luchas. Esto se ha acabado. No hay un sustituto, a nivel de significantes, a nivel del mundo simbólico o del mundo épico, de esta capacidad de movilización que tenían las ideologías. Hay unas cuantas, Hara-Krishna y demás, pero tampoco es tanto como a veces decimos. Son movimientos de tipo más coyuntural, que se van sucediendo unos a otros, beats, hippies, yippies, etc., en una especie de espiral a la baja; por otro lado, el fascismo como forma más globalitaria, consistente, ordena$\mathrm{da}$, simbólicamente trabada y que da sentido a toda la vivencia de un individuo. Lo lamentable es que desde la izquierda no se ha hecho ningún esfuerzo de recrear la capacidad de movilización, de ligar a la gente con un proyecto de sociedad y de ligarla activamente. Esto es muy peligroso, y aprovecho para telacionario con uno de los puntos del guión original que es el de la relación público-privado, puesto que puede producirse una retirada absoluta hacia los espacios, en su sentido más amplio, privados. Tú antes decías que en las casas lo más importante desde algún punto de vista era estos espacios no cualificados. En cambio, ahora, desde el punto de vista del diseño, se está dando mucha importancia a los espacios que antes eran los menos significativos de las vivien- 
das, como la cocina o los baños. Ahora lo primera que se mira cuando se va a comprar o a alquilar un piso es la cocina y los baños. Las zonas «innobles» se están revalorizando, a nivel de la construcción privada, de significados espaciales. Se observa un alza en la valoración de estos espacios privados, incluso desde los pro pios diseñadores.

Pero vas a permitirnos que cambiemos un poco de tema y recuperemos otra vez el hilo de la secuencia tradición-modernidadpostmodernidad. ¿En el proceso de producción del espacio es pertinente hablar de un continuum?

$X$. R. Yo creo que no hay un continuum. No soy nada lefebvriano, pero el hecho de que hay una diferencia entre la producción en el espacio y la producción de espacio es innegable. Ello responde a una ley general según la cual el crecimiento exponencial (de esto hablaba en Ensayos sobre el desorden) de un sector de la realidad hace que este sector de la realidad no pueda servir al contexto, sino que se haya de servir de él. Esto en la revolución industrial está muy claro, tal como explicó Polanyi. A partir de un cierto momento la producción industrial y sistemática de mercancías no puede soportar que haya un mercado meramente ocasional de mano de obra o de capitales. La producción de mercancías ha crecido tanto que no puede dejar que la mano de obta, el consumo, o sea, tanto los medios como los fines, queden dejados a la «natutaleza». Tiene que redefinir al mercado de mano de obra y, por lo tanto, dicta leyes de higiene sobte los trabajadores. En tesumen, el crecimiento exponencial de un sector de la realidad no puede permitirse dejar que el contexto no haya crecido o transformado a su xitmo. Si hablamos de la información también está claro que hay que generar los acontecimientos necesarios para lienar el petiódico o la emisión de turno. El crecimiento de la información, el crecimiento de la producción de mercancías, todos tuvieron una influencia en la redefinición de su contexto para que ésta estuviera de acuerdo con las exigencias productivas del sistema propio. Pensemos, para poner otro ejemplo, en la ciudad. El crecimiento exponencial del tejido urbano ha hecho que Ia ciudad dejase de pertenecer al continuum campo-aldea-ciudad y no pueda ya servir al campo sino que deba servirse de él, transformando así la relación campociudad en una relación puxamente instrumental. Entonces, es dentro mismo de la ciudad donde se tectean este tipo de relaciones instrumentales-unidimensionales: por ejemplo, las relaciones suburbio-centro, y éste sería otro tema que po- 
dríamos introducit, el de las burguesías que han abandonado las ciudades.

R. P. Tomando como dato la producción del espacio que se está efectuando en los momentos actuales, y entendiendo como espacio sagrado aquel que ordena otros espacios y trasciende de sí mismo, ¿hoy habría una emergencia de algún tipo de espacio sagrado agilutinador y ordenador?

X. R. Estáis hablando de un fenómeno que no es necesariamente un espacio. Es más un significante que un espacio. Es un espacio simbólico que sirve como significante polarizador. Lo que pasa es que para salinnos de las generalidades que al respecto se han dicho me gustaría pensarlo. Me tefiero a las «mitologías» del $2 \mathrm{CV}$, del catch, del strip-tease, de la casa de campo, etc.

R. P. Pero ninguno de estos elementos que ha detectado el discurso sociológico son elementos estructuradores a nivel global.

Nos enfrentamọ a la inexistencia de un sistema de sígnificantes ordenadores para la mayor parte del colectivo social. La catedral tenía sentido como espacio sagrado en la medida que existía un sistema de significantes que ordenaban.

X. R. Era un sistema de sistemas. ¿Cuál es el sistema de sistemas, hoy? ¿No setá la informática, quizás?

R. P. Es posible que se trate más de una línea de análisis que no de una respuesta concreta.

$X$. R. Sería una tontería afirmar que no existe este sistema de sistemas. Los discursos que nos estamos haciendo son en definitiva un intento de decir que esta serie de conductas y mecanismos de «el fin de semana» o «la casa de campo» o «los auriculares», todos estos signos sociales, tienen un denominador común, digamos el de buscar un carabio en las relaciones, el dejar de tener una rela. ción funcional con las personas, o el de buscar en un mundo de miedo la supervivencia a través de la similitud, y no a través de la dependencia. En cualquier caso, se trata de la negación de lo «societario». Alain Touraine dice que en Ftancia existe hoy sólo lo privado y lo estatal. Ha desaparecido el espacio societario intersticial, civil. Touraine va buscando una «verdadera» sociedad, y se va a Polonia, con Solidaridad, ${ }^{1}$ como antes se fue a Portugal. $\mathrm{Y}$ es que en Portugal pasó también que durante un tiempo el poder fue dando botes por la sociedad, como una pelota. Aquí

1. N. de R. P.: La entrevista fue realizada con anterioridad al golpe millitar que se produjo es Polonia en diciembre de 1981. 
en España no ha ocurrido eso. Aquí pasó de la vaca a la boca sin intermediarios. Pero Polonia o Portugal han sido sitios en los que parece que el poder ha andado desecuestrado durante un tiempo. Touraine seguro que diría que el elemento «estructurante» por el que preguntáis es, paradójicamente, la desaparición de lo societario como realidad simbóitca. Esto conecta un poco con lo que antes apuntábais de que el espacio es «desde donde», y no «sobre lo que» se habla.

También parece que se acaba el espacio «intelectual», que era aquel en que se producía un discurso teórico, crítico con el poder, etc. Einthoven explica esta situación diciendo que existe una relación inversa entre poder político y poder intelectual. En los momentos en que el poder político es débil (IV República), hay grandes patrones intelectuales (Merleau Ponty, Sartre, Camus, etc.), y en los momentos en los que el poder político se tefuerza (De Gaulle), Ios filósofos empiezan a hacerse más estructuralistas, en definitiva, menos importantes. En este momento en que se vuelve a un neogaullisno, a un poder estatal socialista (que acabará siendo socialdemócrata, pero que tiene aún una retórica socialista como hacía tiempo no se óla, hablando de nacionalizaciones sin vergüenza), vuelve a producirse un descenso en el poder intelectual. Con este teforzamiento del poder estatal se tetrae el espacio de los intelectuales. No hay papel para ellos. La pregunta que deberíamos hacernos nosotros es cómo, en este país en que no se ha producido este fortalecimiento del poder estatal, tampoco tenemos papel. Claro está que hay aquí un elemento que lo preside todo y que en otros sitios no se da: es el miedo.

R. P. Efectivamente, estamos preparando un número de Ia revista dedicado al miedo. Para nosotros es un tema importante y lo estamos preparando con cuidado para no caer en las banalidades que todo el mundo tiene hoy en la boca. Pero volviendo al tema que ahora nos ocupa, esto liga con el tercer punto de nuestro guión. Estás planteando la desaparición de este espacio intermedio, el espacio intelectual, que es en el que propiamente se producen las elabo. raciones simbólicas de la realidad. Nosotros to habiamos planteado como una paradoja entre la ubicación del poder, de las decisiones, que se concentran de forma creciente en hiperespacios, o en espacios no dimensionados, mientras que por otra parte los individuos cada vez más, si se vinculan, lo hacen a movimientos estrictamente referidos a dimensiones concretas, nacionalismos, movimientos de barrio, etc., e incluso se empieza a observer el fenómeno de 
la recomposición de familias integrales y que parece no responder exclusivamente a razones de supervivencia económica. En resumen, mientras el poder, la decisión, cada vez toma menos en cuenta el dimensionalmente espacial, los individuos van restringiendo de forma creciente su espacio de referencia. ¿Cuál puede ser el límite de esta polarización y de esta desaparición de espacios intermedios?

X. R. Me parece una formulación muy precisa. Estos espacios que yo antes llamaba ambiguos o no cualificados (que pueden ser entendidos en términos físicos o no f́́sicos como en el caso de los espacios simbólicos) exigen como condición de posibilidad la mezcla del mundo privado y del mundo público. Estos fenómenos se dan en espacios que no son ni privados ni públicos, ni teóricos ni de poder: son espacios bibridos. La libertad nada más se produce en el solapamiento de dos sistemas. En cierta manera nos encontramos en un mundo en el que la gente se encuentra responsable de todo e impotente delante de todo. Somos responsables de la supervivencia de la especie por un lado, y por otro, somos responsables del equilibrio psicológico de nuestro hijo: tanto de los registros más íntimos de la vida familiar, como del mantenimiento de la vida sobre el planeta. Teóricamente somos responsables de todo y prácticamente somos impotentes delante de todo.

Es a este doble nivel que se debe analizar (que por otra parte no es nuevo: los aztecas eran individuos que se sentían responsables de que el sol no se apagara y eran al mismo tiempo absolutamente impotentes). Yo creo que no sólo nos hemos encontrado con que el fenómeno nos depasa, sino que a través de la penetración ideológicamente hegeliana y prácticamente científica, el nivel de responsabilidad es más radical aun que en el México precolombino. Esta analogía que se me ocurre entre la responsabilidad que tengo con mi hijo y la responsabilidad de la supervivencia de la especie, me deja absolutamente anonadado y con una sensación de impotencia tremenda. En esta situación no hay duda que una solución es ponernos «calentitos», agruparnos, irnos a vivir al campo.

$\mathrm{Y}$ esto se hace hoy a menudo sin ningún tipo de elaboración ideológica. Lo que impresiona es que lo hace la gente sin mensaje.

R. P. Esto es precisamente lo nuevo. No se trata de agrupaciones de vida comunitaria con propósitos verbalizados, sino de la reconstrucción de espacios que podríamos llamar de securización o de 
referencia. En definitiva, de espacios de identificación y de reco nocimiento. El tandem de responsabilidad y de impotencia conduce a un desconocimiento del entorno y de uno mismo y, en definitiva, es lógico que la gente busque esta proximidad del grupo en el que se reconoce y en el que lo reconocen. Esto es susceptible de una lectura reaccionaria, organicista, y por lo tanto, constituye un caldo de cultivo importante para intentos retro. Esta desaparición de espacios intermedios en tanto que individuos, intelectuales o profesionales, marca una tendencia a la polarización de las lecturas y de las interpretaciones simbólicas.

$\mathrm{X}$. R. Las profesiones liberales son un buen ejemplo de esta situación intermedia o de solapamiento entre sistemas. La profesión liberal es «equívoca» por definición, en la medida en que se mueve y vive de un espacio público-privado o instrumental-final, de un espacio medio-fin, de un espacio valor de uso-valor de cambio, etc. Estos tres elementos, la ciudad burguesa, la profesión liberal y el intelectual jugaban en este ámbito. Hoy en día los profesionales buscan el ayuntamiento que los contrate, los intelectuales lo mismo y las familias burguesas abandonan la ciudad.

R. P. Este vacío que se crea es fastidiado porque desde ninguno de los dos polos, el individuo que se pone «calentito» en el grupo y la instancia de decisión y poder que actúa hiperespacialmente, se puede generar un mundo simbólico que actúe globalmente como integrador. A lo mejor es que estamos persiguiendo un fantasma al intentar recuperar, con una lectura moderna, este espacio simbólico integrador y nos resultaría mejor abandonar esta pretensión.

$X$. R. Yo creo que sí, que tendríamos que abandonarla. Lo que pasa es que se puede hacer una poética de abandono que no es más que un modernismo de segundo grado. Pienso en Baudrillard.

R. P. Si no tenemos la posibilidad de elaborar un sistema de significantes, ni hacemos lo poético del abandono de los viejos sistemas y además nos niegan el espacio para hacerlo, ¿estamos condenados al silencio?

X. R. No. Yo estoy hablando de elaborar un sistema de reparación. Nunca me ha gustado hacer la poética de la humildad o la poética del posibilismo, pero la lucidez lo exige. Es muy difícil, y cuesta mucho no huir ni hacia adelante ni hacia atrás, no vestir de gran tragedia a la coyuntura, no hacer la poética del principio del fin, de la vanguardia o de la retaguardia. Cuesta, ciertamente, to live in uncertainty como decía Keats, vivir la realidad nueva sin protegerse, sin cinturón de castidad, sin la protección de las coartadas 
de las «superaciones dialécticas» o las poéticas de los post o retro. Creo que se puede mantener una actitud que no utilice las coartadas y que al mismo tiempo no haga poéticas.

De todos modos, yo estoy convencido de que el pensamiento es ante todo un sistema de protección. Como argumentó Freud, la capa cortical no está hecha para conocer sino para amortiguar las sensaciones que de otro modo hacen daño al llegar directas. En este sentido el cerebro sirve, tanto o tnás que para conocer, para «desconocer». Yo, en mi vida particular, me teconozco este reflejo protectivo. Se me ocuxte una analogía. La masajista que me da masajes para recuperarme un músculo me hace daño cuando toca el músculo en cuestión. El problema que tiene es que cuando hay un punto doloroso, que es precisamente el que ha de tocar y movilizar, el roúsculo se protege. La técnica del masajista consiste en ir trabajando el músculo durante mucho rato, tratando de no provocar la reacción de protección, para al final saber llegar al punto doloroso sin que se produzca la reacción defensiva.

Pues bien, hemos de aprender intelectualmente a trabajar sin generar estos anticuerpos que normaimente generamos cuando un fenómeno nuevo nos sorprende y nos hace no verlo, o decir que es una variante de otro que ya conocíamos.

R. P. Un tema alejado de esto pero que de alguna manera también liga, es el de los espacios de transgresión. En la actualidad no aparecen tan claramente como aparecían en otros momentos. ¿Es que han desaparecido? ¿Podemos sumar esta desaparición a la del sistema de sistemas? $O$ lo que sucede es que se ha dado también una privatización de la transgresión girándola contra uno mismo $\mathrm{y}$, por lo tanto, sin necesidad de una formalización externa en forma de espacio de transgresión.

X. R. Yo creo más bien lo segundo. Es el paso del «catolicismo» al «pro testantismo» a nivel social. Desaparece este espacio social, no hay confesionario, no hay decálogo, y por tanto se produce una responsabilización brutal de uno mismo. Respecto de los hijos es muy claro. Mi padre me servía muy bien como pared. Yo jugaba al frontón. Tiraba la pelota y me la devolvían, tenía algo que era un límite fijo. Mis hijos se encuentran que no tienen pared, y por lo tanto les caen encima todos los paquetes. No tienen apenas fetiches intermediarios (padre autoritario, religión formal, ideatio político) que les eviten la angustia de la responsabilidad subjetiva. Del nacional catolicismo hemos pasado casi sin solución de continuidad al protestantismo social. 